This item was submitted to Loughborough's Research Repository by the author.

Items in Figshare are protected by copyright, with all rights reserved, unless otherwise indicated.

\title{
Integration issues in the development of a modelling and simulation tool for low volume high-complexity electronics manufacture
}

PLEASE CITE THE PUBLISHED VERSION

\section{PUBLISHER}

(C) IEEE

\section{VERSION}

VoR (Version of Record)

\section{LICENCE}

CC BY-NC-ND 4.0

\section{REPOSITORY RECORD}

West, Andrew A., Diana M. Segura-Velandia, Paul P. Conway, David C. Whalley, and Radmehr P. Monfared. 2019. "Integration Issues in the Development of a Modelling and Simulation Tool for Low Volume Highcomplexity Electronics Manufacture". figshare. https://hdl.handle.net/2134/4220. 
This item was submitted to Loughborough's Institutional Repository (https://dspace.lboro.ac.uk/) by the author and is made available under the following Creative Commons Licence conditions.

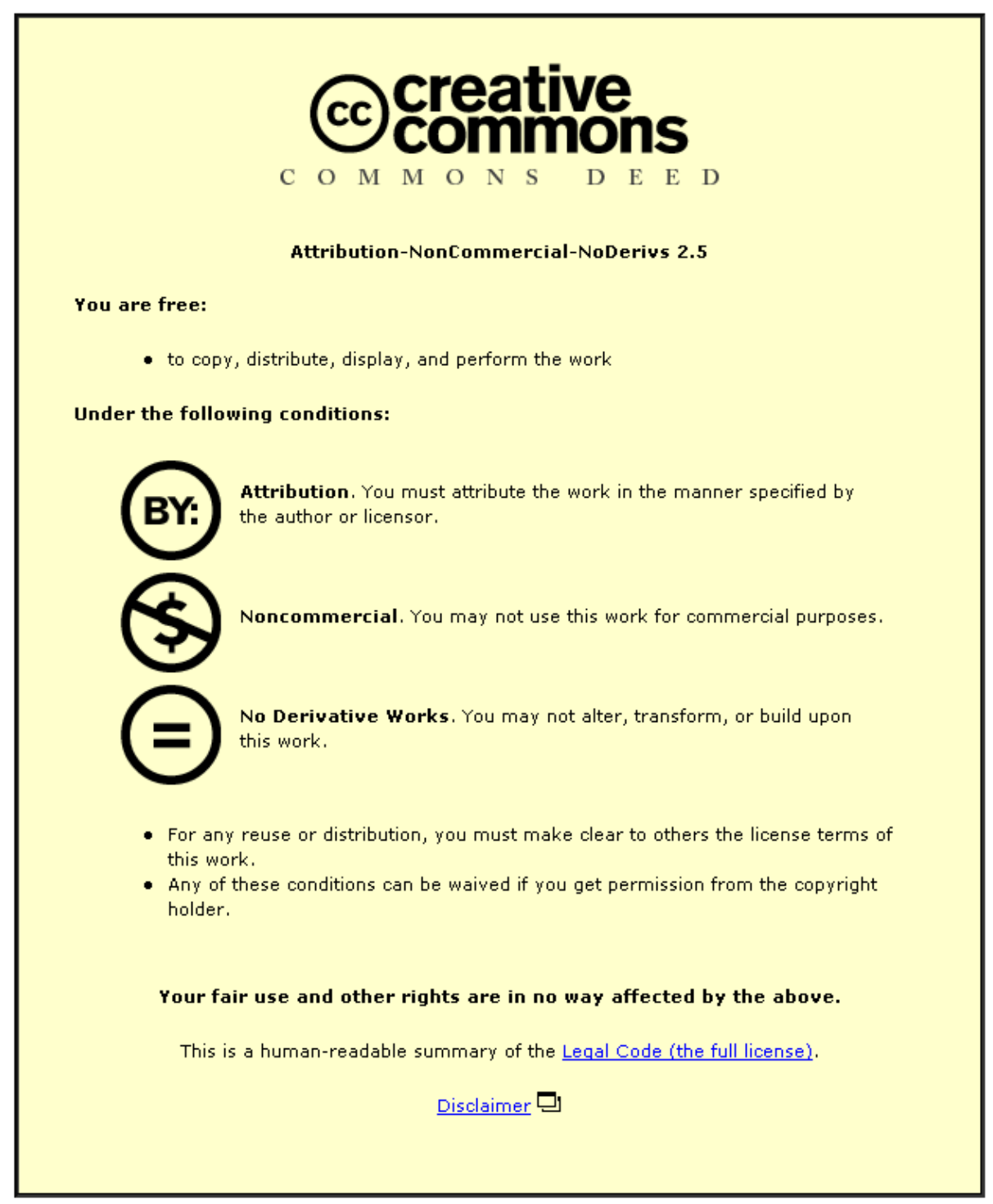

For the full text of this licence, please go to: http://creativecommons.org/licenses/by-nc-nd/2.5/ 


\title{
Integration Issues in the Development of a Modelling and Simulation Tool for Low Volume High-Complexity Electronics Manufacture
}

\author{
D. Segura Velandia*, A. A. West, P. P. Conway, D. C. Whalley, R. Monfared, \\ L. A. M. Huertas Quintero and A. R. Wilson \\ Wolfson School of Mechanical and Manufacturing Engineering \\ Loughborough University, Leics, LE11 3TU, United Kingdom \\ Tel. +44(0)1519 227677 \\ *Corresponding author: \{d.segura@lboro.ac.uk\}
}

\begin{abstract}
In order to design and implement the information systems and modules that could comprise an "industrial strong” knowledge-based tool, links to shop floor systems containing real-time production data and PCA customer information (e.g. bill of materials (BOM), CAD drawings) are required. Details of the issues of implementing the tool in an industrial organisation and the integration of various data sources (e.g. "in-house" developed systems, enterprise resource planning systems, ad-hoc developed databases, machine data and CAD data) are presented in this paper. The application of the CLOVES system in an industrial setup highlights the difficulties in integrating information from design as CAD data and shows how these setbacks could be overcome if the electronics industry were to adopt a common CAD assembly information exchange platform. Hence, this paper concludes that existing automation tool manufacturers should focus exclusively on developing generic connections by adopting industry standards that can facilitate the deployment of "plug and play" tools. This standardisation could in turn help software developers, to provide the electronics industry with more integrated systems that communicate better among loosely coupled information systems and avoid depending on extensive time consuming manual data input.
\end{abstract}

\section{Problem Statement}

Printed Circuit Board (PCB) assembly of low volume high complexity still require a level of manual intervention during product manufacture Both component-level failures and system-level (i.e. noncomponent failures such as defects in design and manufacturing) failures could be the causes of poor first time yield and increased production costs. Systemfailures have not been incorporated in prediction models due to the fact that they are not driven by wellcharacterised deterministic processes.

A project initiated at Loughborough University has been developing a simulation and analysis support tool based on interacting modular components with well defined functionalities and interfaces. The knowledgebased tool enables the characterisation of complete design, manufacturing and business processes (throughout the entire product lifecycle) in terms of their propensity to create defects that could cause product failure to allow dynamic simulation of these models for decision support.
Links to shop floor systems containing real-time assembly data and PCA customer information (e.g. bill of materials (BOM), CAD drawings) are required in order to support the information systems and modules. However, the practical implementation in an industrial organisation of the integration of various data sources (e.g. "in-house" developed systems, enterprise resource planning systems, ad-hoc developed databases, machine data and CAD data stored in a number of formats) in a challenging task. There exists the need for more research that can ease the integration of industrial data in a referenced and structure way that enable the development of software in an open architecture.

This paper demonstrates the issues of implementing graphical user interface in an electronics contract manufacturer (ECM) for component defect data capture and a solution to integration of various CAD data files (e.g. standard ODB++ and FATF file) to a unified data repository are proposed. Furthermore, the necessity of integrating electronics industry's standard data files through a vendor independent application tool is discussed and demonstrated.

\section{Industrial Context and Review of Previous Research}

Several changes in the globalised economy and economic and political pressures have relocated offshore the UK's high volume, low variety manufacture of electronics products. Hence, UK electronics manufacturing has migrated towards supplying low volume solutions to a global market. In order to adapt to evolving market trends, the UK low volume high complex electronics needs to be agile i.e. to maintain good productivity under pressure of uncertainty and flexibility requiring implementation of knowledge-based decision support tools throughout the entire product lifecycle.

Additionally, these globalisation pressures are fragmenting the electronics production network (EPN). As electronics products become more modular in nature, modularised procurement from external supply chains becomes increasingly more competitive, outsourcing becomes more attractive and vertical disintegration and hierarchical structures of modularised product architecture fragments (see Figure 1). 


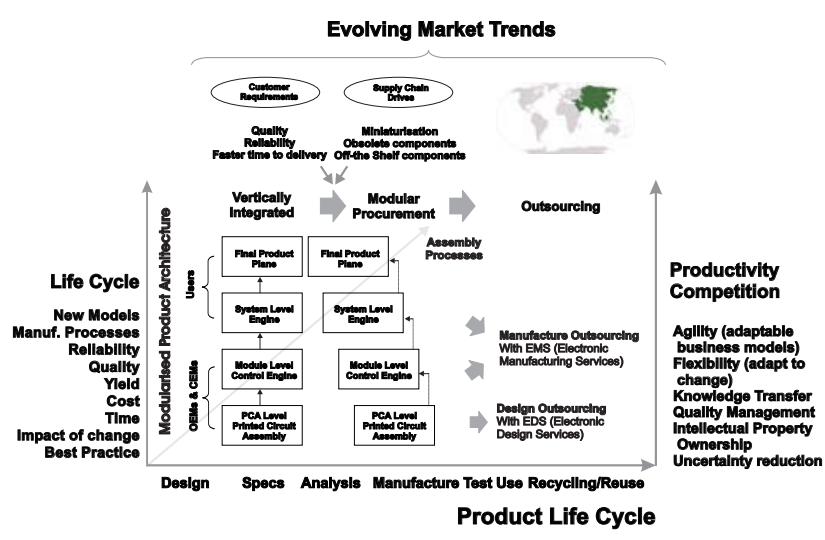

Figure 1. The UK low volume high complex electronics industry context

A project initiated at Loughborough University has been developing a simulation and analysis support tool based on interacting modular components with well defined functionalities and interfaces The tool enables the characterisation of complete design, manufacturing and business processes (throughout the entire product lifecycle) in terms of their propensity to create defects that could cause product failure to allow dynamic simulation of these models for decision support. Enterprise modelling has been employed to support formalised requirements definitions for the modelling [1] and the simulation. A rule-base [2] and case-base [3] knowledge repositories formalise information about PCA design for manufacturing best practice and root-cause analysis of failed cases. The deployment of both theoretical and empirical physical models of STM processes (e.g. printing, placement, reflow) and rework and the use of historical defect data, also support the prediction capabilities of the tool (see Figure 2)

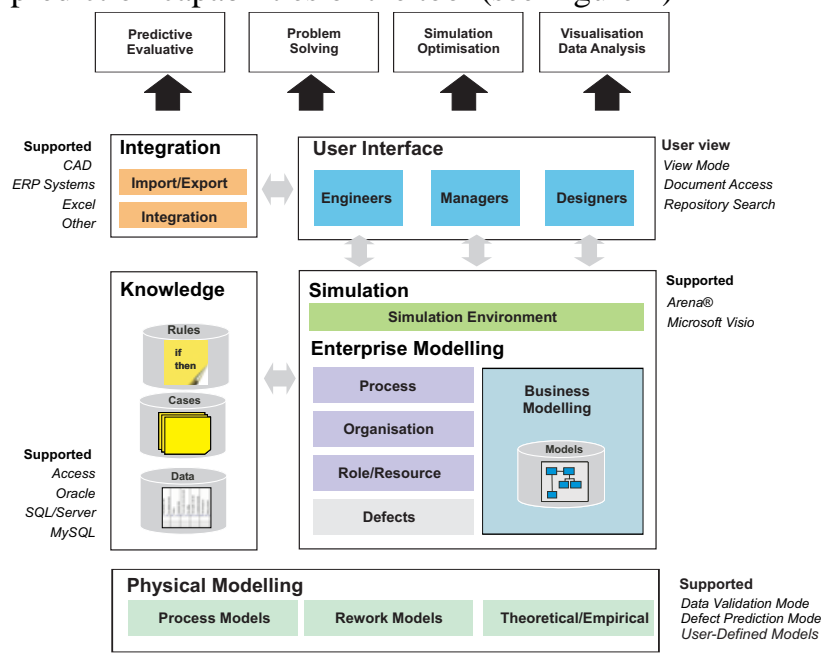

Figure 2. CLOVES Software Toolkit Concept

Full integration of information across the shop floor for a particular assembly in real time has not been achieved. Integration of de-coupled source of information from design and manufacture and other areas of the company (procurement, quality) in real time are required for a company to be agile and to respond efficiently to external (e.g. customer requirements) and internal changes (e.g. traceability).
For the PCB assembly processes the type of information across the life-cycle consists of: CAD data of the printed circuit board, package style of electronic components, machine settings for printing, placement, soldering inspection and testing processes and other assembly data (e.g. stencil thickness, type, and tolerance) (refer to Figure 3). In some companies, part of these data is stored in an Enterprise Resource Planning System (ERP) that support various company's departments (e.g. financial management, customer relations, supply chain management, Sales management and production and scheduling). However, most ERP systems are not deployed to integrate the whole information structure of a company and most importantly the whole history of a PCA in terms of its quality, process history, manual handling and rework processing is not logged making the ERP systems incapable of defect prediction and decision support (e.g. root-cause analysis).

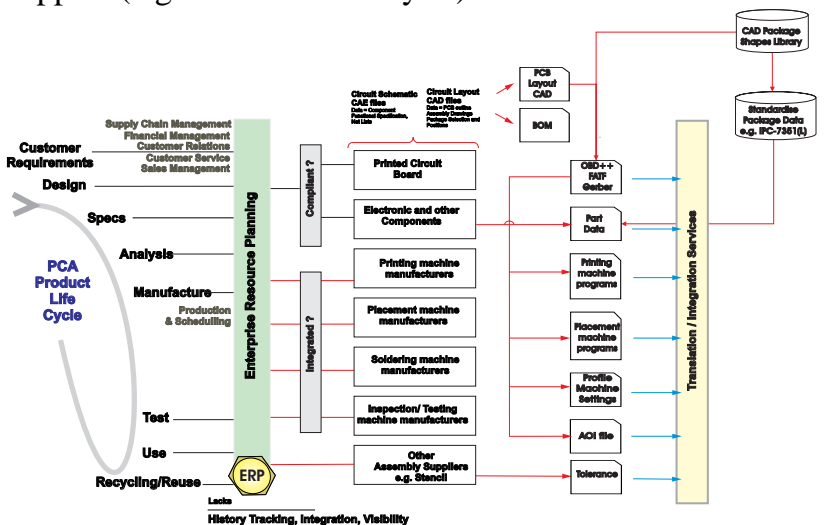

Figure 3. Data for a PCB assembly across its life cycle

The IPC ${ }^{\circledR}$ or the Association Connecting Industries (formerly known as the Institute for Interconnecting and Packaging Electronic Circuits), an organisation aiming at standardising the assembly and production requirements of electronic equipment and assemblies [4], has recently concluded that existing automation tool manufacturers have focused only on their own individual platforms making the (i) intra-communication links between design and manufacturing and (ii) inter-communication between the supply chains and the company laborious [5].

Attempts to overcome these integration issues have resulted in the development of "plug and play" factory enabling technologies (e.g. the Extensible Markup Language (XML), internet) that aim at supporting generic connections between equipment from multiple vendors [6]. However, industry standards are needed to accomplish this integration for various manufacturing and assembly domains. In electronics manufacturing, for instance, the IPC has developed a broad set of document type definitions (DTD) using XML. These data transfer standards are identified as IPC-2510 series [7-9]. In particular, the IPC-2581 is a generic standard that codes a data file format used to describe printed board and printed board assembly products including information about tooling, manufacturing, assembly, and inspection requirements [10]. This XML-based data format is 
derived from the Valor Computerized Systems ODB++ and IPC-2511B GenCAM ${ }^{\circledR}$.

\section{Case Study}

Industrial partners involved in this project come from UK based aircraft electronic subsystem producers. The PCBs assembled are reliability sensitive applications that tend to favour lagging-edge component technologies or military grade package technology in declining volumes. For the purposes of this project data corresponding to the Contract Electronics Manufacture (CEM) partner is presented.

The data used in this paper correspond to proven PCA reliable systems that were developed around two to three decades ago. For this reason, two data formats were analysed in this study: ODB++ from Valor ${ }^{\circledR}$ and a FATF from Fabmaster ${ }^{\circledR}$. These two are standard formats for the EMS under study. The post-processing and integration issues of these two data files to support the CLOVES knowledge-based tools for decision support (e.g. design for manufacture (DfM)) are presented in this paper.

\section{Data Models}

One of the modules in CLOVES aims at applying the simulation tools within the DfM stage of new designs to enable the evaluation of design and manufacture options. The possible scenarios have been described by the authors elsewhere [11]. The simulation data model was derived in the following steps: (i) formalisation of the knowledge to obtain the static models via Enterprise Modelling [12], (ii) the generation of the dynamic models and (iii) the simulation execution in a discrete simulation software (e.g. Arena ${ }^{\circledR}[$ [13]) (refer to Figure 4).

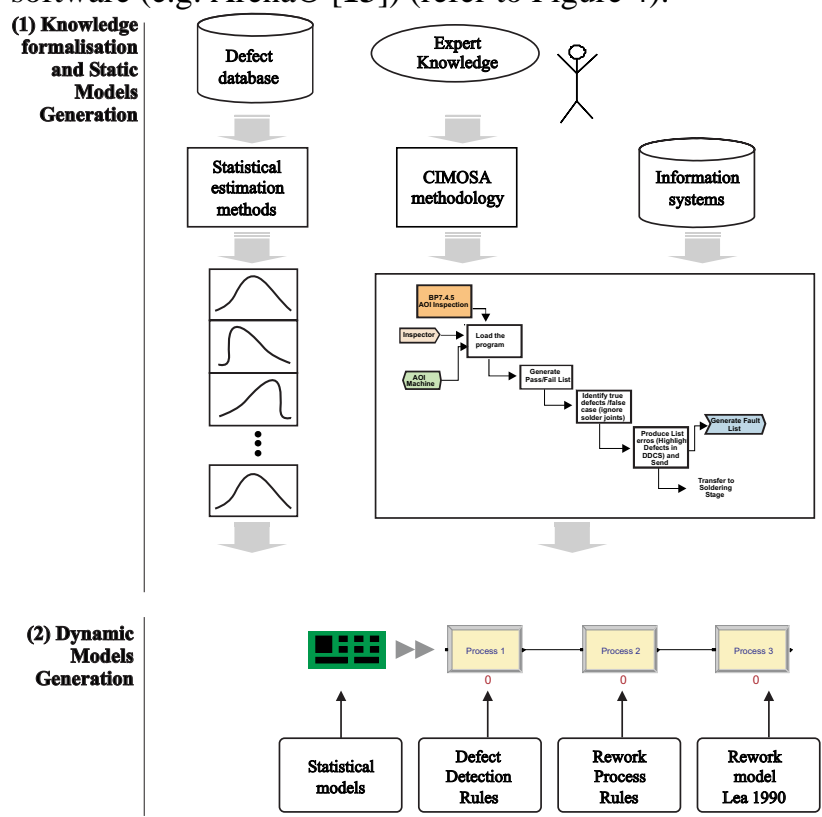

Figure 4. Simulation model

The conceptual data model to support the simulation module comprises the data represented in Figure 3:

- CAD package shapes library

- PCB layout cad files

- $\mathrm{BOM}$
- $\quad$ Standardised package data

- Part data

- FATF / IDF / GERBER files

- Paste printer programs

- $\quad$ SMT placement machine programs

- Reflow oven programs

- Test programs, and

- Component defect data

Component defect data are captured via a graphical user interface (GUI) that represents the assembly drawing and enable to record component faults for PCB assemblies on both sides as it is shown in Figure 5.

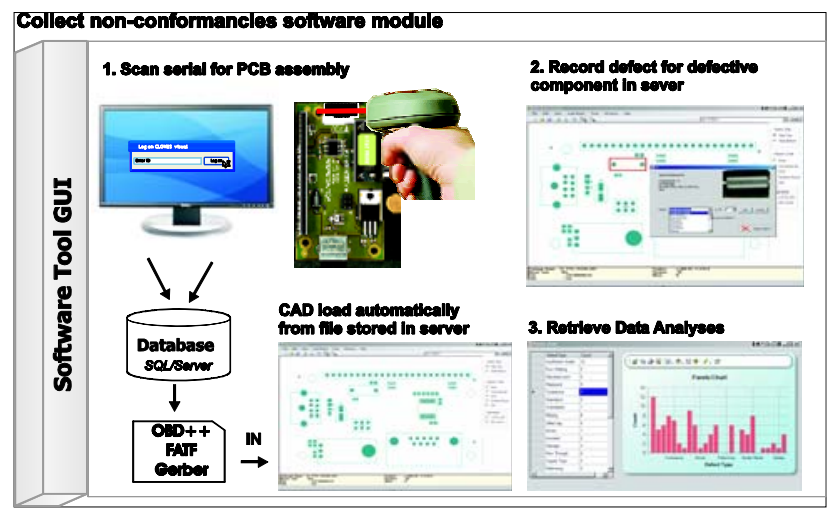

Figure 5. CLOVES defect data entry tool

The conceptual data model described above was integrated from various data sources as shown in Figure 3 and the data was stored in a SQL database.

\section{Collecting non-conformances}

In a typical factory production engineers and quality engineers require data form the assembly, test and rework processes from diverse sources and in a variety of formats. The data required to trace defects to root cause links necessarily to the CAD data (e.g. position of the component on the board).

CAD data from customers are seldom complete and correct for use at the assembly stage. While quality engineers do not need electronic component information values and tolerances, they do need information on standardised package data, pin count, component $\mathrm{x}, \mathrm{y}$ coordinates. The availability of data provides the quality engineer with the data required to derive information and trends that can shed some light on the root cause of a particular defect.

At present time, CAD data are entered manually to defect analysis tools from drawings, files, and the internet into spreadsheets or ad hoc databases. This process can be very slow if the factory's device names do not match device names in the CAD data. Quality engineers need a single data source to reduce the time spent of entering data which can be used for analysis tasks. Additionally, there is a need of centralise data to avoid the duplication of data that in most cases has already been entered in a Management Resources Planning (MRP) system and to manage formalised tools that avoid the problems that come with the use of decoupled information systems. 
The degree of completeness and the structure of the two studied CAD data files to populate the database and to generate the defect data entry interface have a high impact on the performance of the programming effort.

While the completeness does not depend on the CAD format, as it is usually a consequence of the CAD designer and CAD engineer thoroughness, the structure of the ODB++ and the FATF file differ widely, hence making difficult to integrate board data from CAD systems for use in board assembly quality processes.

These two files have been integrated to provide an interactive graphics CAD system to enable component defect recording and data analysis. The overall structure of the OBD++ and fatF files differ in structure as it is shown in the following figures.

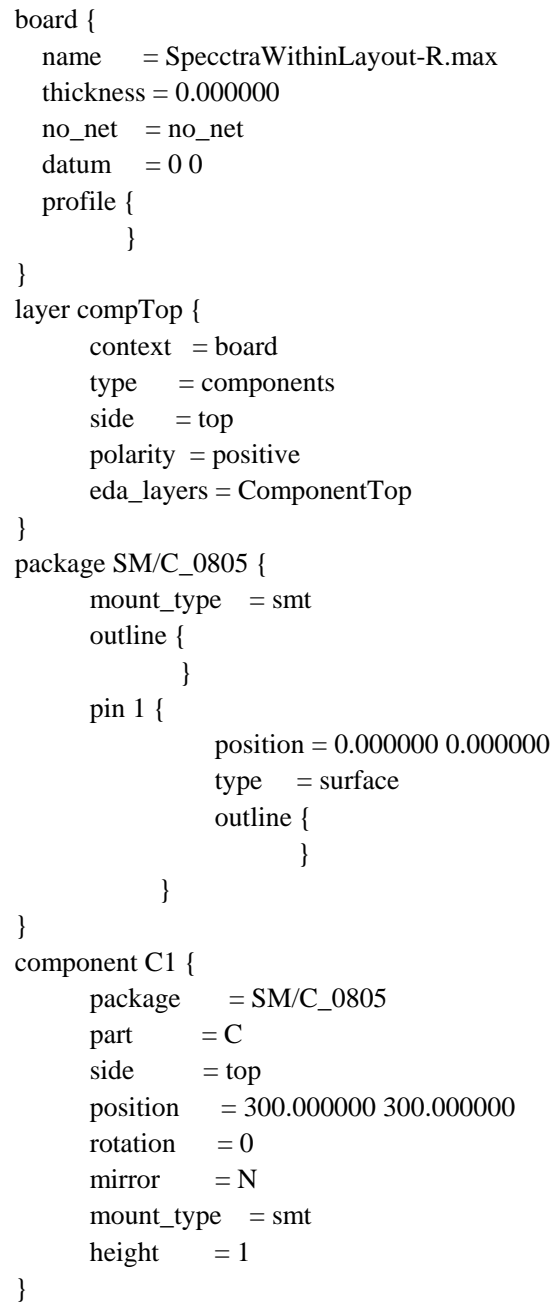

Figure 6. ODB++ file example

:BOARD_DATA

1,"JOB" (JOB_NAME,VERSION,CREATED,MODIFIED);

2,"CONTOUR" ((X1,Y1,0),(X2,Y2,0),...,(Xn,Yn,0));

:EOD

:PARTS

PART_Id,PART_NAME,DEVICE_NAME,PACKAGE_NAME,X, Y,ROTATION,T_OR_B;

PART_Id,PART_NAME,DEVICE_NAME,PACKAGE_NAME,X, Y,ROTATION,T_OR_B;

:EOD

:PACKAGES
PACKAGE_ID,PACKAGE_NAME,XMIN,XMAX,YMIN,YMAX, ("LABEL"(FONT_ID,X,Y,JUSTIFY,ROTATION) ),

("PINS"(PIN_id,PIN_NAME,PIN_X,PIN_Y,PIN_TYPE),..., (PIN_id,PIN_NAME,PIN_X,PIN_Y,PIN_TYPE) )

(PIN_id,"PAD" (PAD_STACK_ID,((X1,Y1),.. ,(Xn,Yn))), SYMBOL)),..., PIN_id,"LAYER"(LAYER_ID,(SYMBOL,..., PIN_id,"LAYER"(LAYER_ID,(SYMBOL, ... SYMBOL)) ) ;

PACKAGE_ID, (...............);

:EOD

Figure 7. fatF file example

\section{Conclusions}

The integration of the CAD data using the ODB++ was easier to implement than the fatF specification. Although both data file have describe a PCA with details sufficient for assembly requirements, the ODB++ XML structure specifies data elements specifically designed to enable the information exchange related to the data needed by assembly, inspection and quality. This hierarchical structure also facilitated the reading and writing of all features defined for the requirements of the defect data entry module.

The ODB++ structure therefore appears as a more robust file to integrate in any software module that requires CAD information for a given product.

\section{Acknowledgments}

The authors wish to express their gratitude to the industrial collaborators. This work was supported financially by the IeMRC DISCOVER grant, SP/05/01/02 and DTI CLOVES grant, TP/3/DSM/6/I/16333.

\section{References}

1 Monfared, R.P. Practical Application of Enterprise Modelling. 2003: Wolfson School of Mechanical and Manufacturing Engineering, Loughborough University.

2 Efstathiou, J., 1989. Expert systems in process control. Harlow: Longman in association with the Institute of Measurement and Control.

3 Segura Velandia, D.M., A.A. West, P.P. Conway, et al. A Case-Based Reasoning Approach for Low Volume, High Added Value Electronics. In: 8th Electronics Packaging Technology Conference, EPTC. 2006. Pan Pacific Hotel, Singapore, 843-848.

4 2008. [online]. Available from http://www.ipc.org/ [Accessed 2008].

5 2006-2007 IPC International Technology Roadmap for Electronic Interconnections. Volume 1 Trends and Issues. 2007, IPC.

6 Dugenske, Fraser, Nguyen, et al., 2000. The National Electronics Manufacturing Initiative (NEMI) plug and play factory project. International Journal of Computer Integrated Manufacturing, 13(3): p. 225244.

7 Delamer, I.M. and J.L. Martinez Lastra, 2006. Quality of service for CAMX middleware. International 
Journal of Computer Integrated Manufacturing, 19(8): p. 784-804.

8 Spera, J., 2002. Making Sense of CAMX Initiatives A new solution improving information availability is allowing manufacturers to distinguish themselves as uniquely efficient in the maturing market. Electronic packaging and production, 42(11): p. 20.

9 2002. IPC-9261, In-Process DPMO and Estimated Yield for PWAs. IPC.

10 IPC. IPC-2581 - with Amendment 1. Generic Requirements for Printed Board Assembly Products Manufacturing Description Data and Transfer Methodology [online]. 2007. http://webstds.ipc.org/2581/2581.htm

11 Wilson, A.R., A.A. West, D.M. Segura Velandia, et al., 2008. Complex Low Volume Electronic Systems: Addressing the Knowledge Gaps for UK Production of Aircraft Electronic Subsystems. Proceedings of the I MECH E Part B Journal of Engineering Manufacture, [in publication].

12 Kosanke, K. and M. Zelm, 1999. CIMOSA modelling processes. Computers in Industry, 40(2-3): p. 141153.

13 Arena. v.11.00.00-CPR7 ed. 2007, Rockwell Automation

Technologies. http://www.arenasimulation.com/ 
